\title{
ESTEREÓTIPO, ESTIGMA E PRESERVAÇÃO DE FACES: A REALIZAÇÃO AFRICADA DE OCLUSIVAS ALVEOLARES SEGUIDAS DE GLIDE PALATAL EM UMA COMUNIDADE ESCOLAR DE ARACAJU/SE
}

Thaís Regina De Andrade Corrêa (UFS)

Resumo: Estudos evidenciam que a realização africada de oclusivas alveolares antecedidas por glide palatal é sensível à avaliação social, configurando-se um estereótipo de estigma social. Objetivamos averiguar os efeitos de polidez de uma variante do tipo estereótipo, em contextos de preservação de faces, em uma comunidade de práticas escolares de Aracaju/SE. Para a constituição do corpus, realizamos 32 gravações de interação conduzida em rede social, e 20 gravações de entrevistas sociolinguísticas. A distância social atuou significativamente, pois quanto mais distante os interlocutores, mais procuraram automonitorar-se, o que se reflete no uso da variante africada. 0 resultado reforça que a variante é um estereótipo de estigma social na comunidade.

Palavras-chave: Palatalização; Estereótipo; Estigma; Polidez.

Abstract: Studies have highlighted that affricate realization of alveolar stops follow by palatal glides is responsive at social evaluation, characterized as a stereotype with social stigma. We aim verify politeness effects over stereotype variant in face threatening contexts, in a school community of practice from Aracaju/SE. To corpus constitution, we collected 32 records of focal group in social networks between the members of the community and 20 sociolinguistic interview with the members. Social distance also were a significative effect: if distance between the speakers is biggest, more is the monitoring, in order to preserve the positive face. This reflects in the use of affricate stops: between speakers with more social distance. The result reinforces that the affricate stop is a stigmatized stereotype in the community.

Keywords: Palatalization; Stereotype; Stigma; Politeness. 


\section{INTRODUÇÃO}

A palatalização de oclusivas alveolares é um processo que ocorre em diferentes ambientes fonológicos e cujos resultados distribucionais apontam fronteiras sociais e dialetológicas no português falado no Brasil. É tomada por objeto em estudos de base variacionista ou dialetológica e seus resultados são generalizados, tanto como índices de pertencimento, como direcionais de mudança linguística. Embora o processo fonológico seja o mesmo, a depender do ambiente fônico (se regressivo ou progressivo), as variantes [t]] e [dz] carregam significados sociais diferentes. A aplicação da regra de palatalização quando realizadas diante de /i/, em contexto fônico regressivo, na região Nordeste é considerada de prestígio, no entanto quando antecedida pela semivogal /i/, em ambiente fônico progressivo, é identificada como estereótipo, muitas vezes, negativo.

Tomemos, portanto, a realização africada das oclusivas alveolares /t/ e /d/ antecedidas por glide palatal, como nas palavras /muito/ e /muit]o/, /doido e /doidzo/, as "africadas baianas" na designação de Mota (2008b), tal traço linguístico está associado ao falar da região Nordeste como um todo, mas mais expressivo nos estados de Sergipe, Alagoas e interior da Bahia. A distribuição de frequência de uso quanto aos perfis sociodemográficos de estratificações sociais 
amplas sugere que o traço é um estereótipo, nos termos de Labov (2008[1972]), por ser predominante no conjunto de indivíduos de menor escolarização e de maior faixa etária.

Em estudo anterior, em uma comunidade de práticas no interior do estado de Sergipe (FREITAG, 2015a), caracterizada pelas polarizações de escolaridade e faixa etária, evidenciamos que a variante africada em ambiente progressivo é um estereótipo na comunidade, mas não necessariamente negativo, visto que praticamente todos os seus membros compartilham desse traço linguístico, o qual pode estar relacionado à marca identitária da comunidade.

Corrêa e Ribeiro (2018) desenvolveram um teste piloto de percepções e atitudes linguísticas sobre a palatalização da oclusiva / $t$ / nos dois ambientes fonológicos (progressivo e regressivo). Esse teste foi aplicado em falantes sergipanos e os resultados obtidos foram: que a palatalização diante de /i/ foi avaliada de forma positiva na comunidade, como sendo de pessoas escolarizadas, formais, residentes da capital e que falam bem e bonito, enquanto a palatalização antecedida por glide foi avaliada de forma negativa como sendo típica de pessoas do interior, de baixa escolarização, que falam informalmente. Estes resultados corroboram com o estudo realizado por Freitag e Santos (2016) também por meio de teste de percepção acerca deste fenômeno com universitários aracajuanos. 
Conforme apontam esses resultados de avaliação social das variantes estudadas, o estigma ou o prestígio que a variante tem depende da comunidade, visto que, o que é estigmatizado em uma comunidade, necessariamente não é em outra, tal como o prestígio.

Nessa perspectiva, apresentamos o resultado de uma investigação acerca do fenômeno, tomando como amostra a fala de estudantes do Colégio Estadual Atheneu Sergipense, em Aracaju, Sergipe. Nosso objetivo é averiguar o quanto a variável estereótipo (a realização africada, /muit]o/, /doidzo/) é sensível à avaliação social, especialmente em contextos de preservação de faces.

\section{ESTEREÓTIPOS, PRESERVAÇÃO DE FACES E POLIDEZ}

Estudos de comunidades de práticas e de redes sociais são capazes de prover informações mais minuciosas sobre a variabilidade linguística realizada pelos falantes, em especial ao que se refere às partes menos formais do repertório linguístico. Rede social e comunidades de prática são duas das forças que movem o processo de mudança linguística e é justamente nesses grupos sociais que o indivíduo ganha evidência no processo de mudança (BATTISTI, 2014).

Na mesma perspectiva, Eckert e McConnell-Ginet (2010[1992]) observam que, nas redes de relações sociais, 
os problemas cotidianos mudam, e da mesma maneira acontece com as pessoas. Mesmo que as pessoas se relacionem localmente com mais intensidade, e conheçam a maioria dos membros da comunidade da qual fazem parte e esses mesmos membros as conheçam também, os indivíduos movimentam-se, engajam-se em diferentes empreendimentos e em diversas comunidades, nas quais processos simbólicos e relações identitárias variadas têm lugar, o que evidencia a ligação entre redes e práticas sociais na variação e mudança linguística.

Quando um falante estabelece uma conversa informal junto ao seu interlocutor, revela muito mais do que foi dito no conteúdo verbalmente expresso. Nesse tipo de conversa, existem informações linguísticas bem marcadas que chamam a atenção, muitas das quais são alvos de avaliações sociais estereotipadas. Por isso, o falante está em constante processo avaliativo, seja de forma consciente ou não. Embora no processo da variação as formas linguísticas diferentes tenham o mesmo valor de verdade ou representacional, a elas podem ser atribuídas avaliações ou valorações sociais diferenciadas, as quais se dão por meio das pressões sociais que operam constantemente sobre a língua, "não de algum ponto remoto no passado, mas como uma força social imanente agindo no presente vivo" (LABOV 2008[1972], p.21). 
Considerando a avaliação social e o nível de consciência dos falantes, Labov (2008[1972]) trata da avaliação em três níveis de consciência: os indicadores que são traços linguísticos que não exibem nenhum padrão de alternância estilística e que tem pouca força avaliativa na sociedade; os marcadores são traços linguísticos que exibem estratificação tanto estilística quanto social, estão abaixo do nível de consciência, e por isso suscitará respostas regulares em testes avaliativos; os estereótipos são traços fortemente marcados dentro da sociedade e propensos a julgamentos muito mais rigorosos e taxativos.

Com bases nos níveis de consciências, trabalhamos os estereótipos, os quais são construídos socialmente e se caracterizam como crenças, julgamentos ou sistemas conceituais. Eles são avaliados por dois vieses negativo e positivo, quando negativo, vincula-se às questões relacionadas ao preconceito e à tensão entre grupos sociais; quando positivo, relaciona-se às questões de identidade social e pertencimento (Leite, 2011). Ao tratarmos da avaliação social de estereótipos nas comunidades de práticas, no que se refere à interação entre os indivíduos, podemos levar em consideração fatores de ordem pragmática, como a expressão polidez, uma atividade estratégica racional, decorrente da necessidade que o homem tem de manter 
o equilíbrio em suas relações interpessoais, leva-o a usar um conjunto de estratégias linguísticas, a fim de evitar ou reduzir ao mínimo o conflito com seu interlocutor (BROWN; LEVINSON, 2011[1987]). Ao estabelecer uma interação com alguém e a depender da intimidade e do grau de proximidade social que se tenha, os interlocutores sabem que têm uma imagem a preservar durante uma conversa, pois o outro só poderá conhecê-lo a partir do que ele revela ser.

Conforme os autores, as interações são as situações mais propícias para os conflitos, e é justamente nessas situações que buscamos proteger nossa face contra possíveis danos quando interagimos com os outros; danos esses que podem ser causados pelos atos que ameaçam as faces tanto do falante, quanto do ouvinte, no momento das interações. Para Brown \& Levinson (2011[1987]), a face que apresenta o lado negativo está relacionada à nossa intimidade e ao desejo de não imposição, já a que apresenta o lado positivo se relaciona à imagem que queremos passar socialmente, a que queremos apresentar aos outros, com o intuito de ter o reconhecimento ou aprovação. Por isso que a face que apresentamos para o outro nas interações que estabelecemos é o que faz com que nossa autoimagem seja construída socialmente.

A depender de como uma variante linguística seja avaliada socialmente por um indivíduo ou determinado grupo, isso 
pode implicar na construção da face daqueles que fazem uso ou não de tal variante linguística, pois os interlocutores procuram ao máximo preservar tal face. Uma das estratégias de preservação de faces é o monitoramento linguístico, especialmente relacionado à realização de estereótipos negativos na fala ${ }^{1}$.

Como as africadas antecedidas por glide são vistas, muita das vezes, com estigma, os falantes, por hipótese, procuram apresentar para o seu ouvinte a sua face positiva, pois é a partir do que se vê ou ouve que construímos a imagem do outro. Vejamos o excerto (1), retirado da amostra da comunidade do Atheneu Sergipense, que evidencia o juízo estigmatizado atribuído à variante africada.

Doc: Na língua portuguesa a questão da variação linguística que você pode falar que uma mesma palavra tem várias pronuncias, mas que é o mesmo significado por exemplo... quando você fala biscoito você vai entender o que é que eu estou pedindo a você e se eu falar biscoitfo você vai entender o que eu tou pedindo a você mas essa diferença que tem entre uma palavra e outra

1 Estudos têm evidenciado os efeitos de polidez como uma variável pragmática nos processos de variação e mudança linguística, especialmente na correlação entre sexo/gênero (FREITAG, 2015b). A forma de futuro do pretérito, em português, está relacionada com a expressão da polidez, função que é inclusive descrita em compêndios gramaticais (ARAUJO; FREITAG, 2015). Procedimentos de coleta de dados com ênfase nos efeitos pragmáticos e sociolinguísticos para captar os efeitos de polidez permitiram evidenciar que há diferenças em relação ao uso do futuro do pretérito como função de polidez quanto à distância social e ao sexo/gênero. A variação entre nós e a gente, já estudada do ponto de vista sociolinguístico, pode ser verificada também por meio dos estudos pragmáticos (SANTOS; FREITAG, 2016; MENDONÇA; FREITAG, 2016), considerando a influência de contextos mais polidos e contextos menos polidos na frequência de uso das formas nós e a gente. 
essa diferença sonora o que você acha? Se você no seu grupo da escola falasse assim?

ELE-F: ah seria zuação porque as pessoas quando você fala uma palavra errada elas começam a zuar

Doc: Aí se eu começasse a falar aqui oitentfa carros se eu tivesse oitfo reais ELE-F: acabam zuando vira motivo de zuação quando fala você alguma palavra que eles não estão acostumados a ouvir palavras diferentes principalmente se você era do interior e veio para cidade e você começa a falar quer queira quer não você sempre pega um pouco do sotaque do local de onde você mora então quando você começa a usar aquele sotaque do interior aqui você acaba sendo discriminado então você tem que se adaptar ao máximo ao modo como as pessoas naquele novo determinado local. (Ele-F, F, E, A, 320)

(2)

Doc: Quando você escuta uma pessoa falando assim biscoit\}o, doidzo, defeit\}o. VIN-M: acho engraçado

Doc: você não adaptaria ao seu vocabulário por quê?

VIN-M: porque eu acho feio Doc: feio?!

VIN-M: acho feio, engraçado. (Vin-M, M, A, 289)

Estes excertos, parte de questões de atitudes linguísticas que compõem o roteiro de entrevista sociolinguística adotado na coleta de dados, sugerem que a realização 
africada não é bem aceita dentro do grupo, o que nos leva a uma investigação mais aprofundada acerca da ocorrência do fenômeno em análise no repertório linguístico desta comunidade.

\section{PROCEDIMENTOS METODOLÓGICOS}

O Colégio Estadual Atheneu Sergipense é a mais tradicional instituição de ensino de Sergipe. Fundado em 1871, inicialmente era escola secundária e preparatória para o curso superior e o curso Normal de formação de professores. Atualmente, a instituição atende apenas ao ensino médio, com cerca de 1100 alunos. O colégio oferece o ensino regular e conta com uma matriz curricular com disciplinas optativas, projetos direcionados à área das artes, educação física e projetos laboratoriais. O alunado da escola é constituído por moradores da capital e da grande Aracaju.

Para a constituição do corpus da comunidade do Atheneu Sergipense, a metodologia adotada foi a de interação conduzida (ARAUJO; SANTOS; FREITAG, 2014), uma vez que somente a metodologia sociolinguística clássica, aos moldes labovianos, por si só, não seria suficiente para mensurar os valores da polidez. A metodologia de interação conduzida permite controlar o grau de distância social entre um interlocutor e outro, além das relações de poder - neste 
caso, quem domina o tópico da conversa no momento que é estabelecido o diálogo - e o custo de imposição, ou seja, o custo de falar sobre o que estava sendo proposto, e a relação com o sexo/gênero dos interlocutores. Tais fatores são apontados por Brown \& Levinson (2011[1987]) para a análise de quais estratégias de polidez os falantes utilizam nas diferentes relações interpessoais.

Os procedimentos da coleta de dados realizada estão detalhadamente descritos em Freitag et al (2016). Foram realizadas 32 interações conduzidas e 20 entrevistas sociolinguísticas, aos moldes labovianos, com um roteiro de perguntas. As duas amostras coletadas constituem o banco de dados Falares Sergipanos (FREITAG, 2013; FREITAG; MARTINS; TAVARES, 2012).

O corpus constituído pelas 20 entrevistas sociolinguísticas e 32 interações conduzidas foi examinado a fim de identificarmos ambientes linguísticos de oclusivas dentais /t/ e /d/ antecedidas de glide palatal/j/. Identificamos 2.504 palavras possíveis de serem palatalizadas no ambiente analisado, e correlacionamos as ocorrências às variáveis linguísticas controladas (grau dos nomes, ambiente da palatalização, classe gramatical) e extralinguísticas (gênero/sexo, local de residência, tipo de coleta, distância social e simetria da interação) e submetemos ao tratamento estatístico do programa Goldvarb X (SANKOFF; TAGLIAMONTE; SMITH, 2005). 


\section{RESULTADOS}

Na amostra analisada, o percentual de realização africada - a variante estereótipo negativo - equivale a 10\% do total (n = 2504), com 256 ocorrências. Este resultado é sensivelmente menor do que o obtido em outra comunidade, no interior do estado que foi de 32\% (FREITAG, 2015a). Esta diferença, em princípio, pode ser explicada pelo fato de a amostra do Atheneu Sergipense ser formada por estudantes do ensino médio, e a amostra da Mãe da Divina Graça ter formação heterogênea, não só quanto à escolaridade - de analfabetos a curso superior - mas também quanto à faixa etária.

$\mathrm{Na}$ distribuição das ocorrências por indivíduo (gráfico 1), dos 32 informantes, 7 apresentam comportamento categórico em relação à realização oclusiva, todos moradores de Aracaju. Há, também, informantes que apresentam índice de recorrência da variante africada muito baixo, como Ele-F $(1 / 80)$ e Jac-F (1/82). Por outro lado, há informantes com alta recorrência da variante africada, como Eva-F (47/109 $=43 \%)$, com percentual de realização superior do que o da comunidade Mãe da Divina Graça (38\%). Ao analisar os dados da informante Eva-F, percebemos que esse fenômeno é recorrente dentro de seu grupo de amigos: Gle-F $(46 / 182=25 \%)$, San-M $(11 / 128=8 \%)$ e Léo-M $(5 / 82$ = 65). 
Os quatro informantes são amigos e estudam na mesma turma e constituem o mesmo grupo de coleta de dados. Pela frequência de uso da variante africada, é possível que o traço não seja um estereótipo negativo para esses informantes, afinal, o que é desprestigiado para um determinado grupo não necessariamente é desprestigiado por outro.

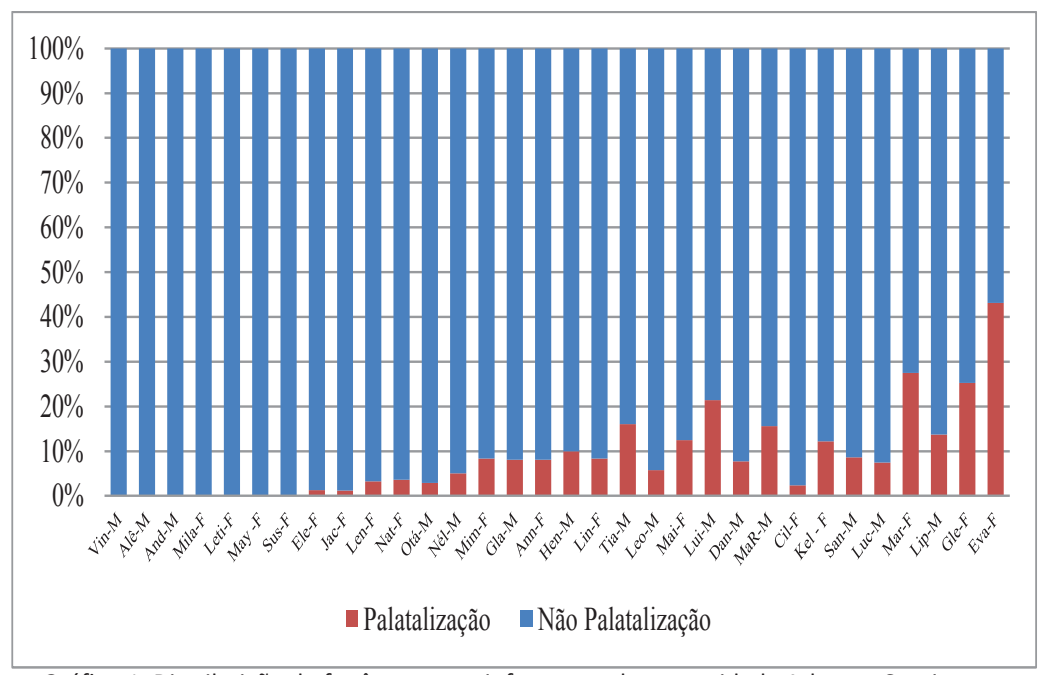

Gráfico:1: Distribuição do fenômeno por informante da comunidade Atheneu Sergipense.

\section{AMBIENTE LINGUÍSTICO}

Do total de palavras, 68\% (1731/2504) são ocorrências de muito e suas flexões. Por conta da alta frequência, a análise destas ocorrências foi realizada separadamente (FREITAG, 2015a). As dispersões (figura 1) mostram o comportamento diferenciado dos dois subconjuntos de dados: muito e flexões e demais palavras. O tamanho dos quadrados é proporcional 
ao número de ocorrências de uma célula, e a posição próxima às extremidades do gráfico sinalizam que o modelo não está ajustado de modo variável (TAGLIAMONTE, 2006).

Os dados para muito e flexões são fortemente polarizados em relação à variante oclusiva, que foi considerada o valor de aplicação. Já as demais palavras apresentam maior dispersão, indicando maior variabilidade.

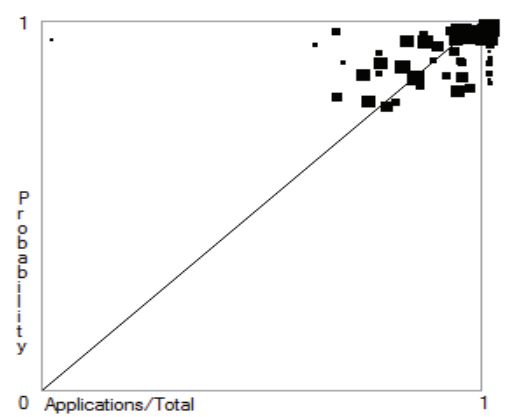

Muito e flexões

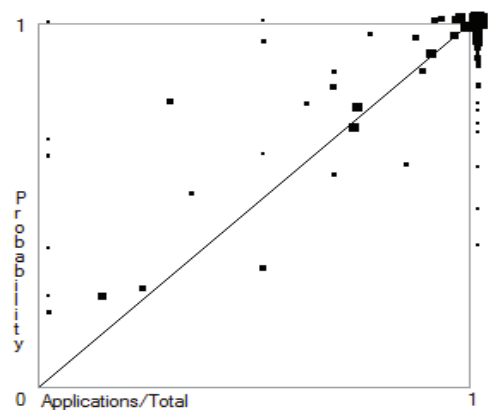

Demais palavras

Figura 1: Dispersões da realização oclusiva em muito e flexões e nas demais palavras.

O comportamento diferenciado na dispersão, além da alta frequência, pode ter condicionamentos internos e externos. A análise do conjunto das outras palavras apontou influência de dois fatores de natureza linguística: o vozeamento e o "grau" dos nomes, respectivamente primeiro e quarto na ordem de cinco fatores apontados como estatisticamente significativos (level $0=0,89$, Log $=-273,956$ ).

Semelhantemente a este resultado foi o de Mota (2008b), que verificou que a palavra muito e suas flexões foram as 
que mais condicionaram à realização das africadas baianas na fala de quase todos os informantes das quatro capitais do nordeste: Aracaju, Recife, Maceió e Salvador. A autora justifica esse resultado não só pela palavra em questão ser um advérbio ou um determinante, mas também pela frequência com que ocorre nas diferentes faixas etárias e em diferentes níveis de escolarização. Embora a frequência de uso da palavra proporcione maior recorrência das africadas, isso não significa que a palavra muito realizada de forma africada não carregue estigma, assim como /biscoit]o/, /

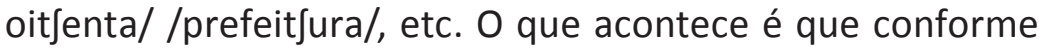
Bybee (2001) as palavras com uma alta frequência têm representações mais fortes e são mais facilmente acessadas e menos propensas a sofrer avaliações. A frequência com que as palavras individuais são usadas e que certos padrões se repetem na língua acaba afetando a representação mental e, em alguns casos, a forma fonética real das palavras. Segundo a autora, se as representações fonéticas forem modificadas gradualmente, as palavras de alta frequência mudarão a uma taxa mais rápida do que as palavras de baixa frequência e o efeito disso é automatizar a produção.

A análise do subconjunto das demais palavras permite 0 controle do vozeamento da oclusiva passível de ser africada (o que não é possível com muito e suas flexões, todas com ambiente desvozeado /t/). 


\begin{tabular}{|l|l|l|l|}
\hline Ambiente & Apl./total & Percentual & Peso Relativo \\
\hline /t/ & $610 / 649$ & $94 \%$ & 0,60 \\
\hline /d/ & $92 / 140$ & $66 \%$ & 0,13 \\
\hline Total & $702 / 789$ & $89 \%$ & - \\
\hline $\begin{array}{r}\text { Input }= \\
0,951 \text { Log }= \\
-173,713 \text { Sig. } \\
=0.000\end{array}$ & & & \\
\hline
\end{tabular}

Tabela 1: Atuação do ambiente

O ambiente de oclusiva vozeada é pouco produtivo na amostra (13\% do total dos dados), no entanto, mais produtivo do que na amostra da comunidade Mãe da Divina Graça, onde é de 3\% (FREITAG, 2015a). Ainda assim, o resultado é convergente, indicando que o ambiente vozeado é mais propício à realização africada do que o ambiente desvozeado, mais propício à realização oclusiva.

As palavras de base nominal que são passíveis de derivação com o sufixo -inho ("grau" diminutivo) também se mostram mais sensíveis à realização africada do que as palavras de "grau" normal.

\begin{tabular}{|l|l|l|l|}
\hline “Grau" das palavras & Apl./total & Percentual & Peso Relativo \\
\hline Normal & $481 / 551$ & $87 \%$ & 0,52 \\
\hline Diminutivo & $9 / 14$ & $64 \%$ & 0,07 \\
\hline Total & $490 / 565$ & $87 \%$ & - \\
\hline \multicolumn{4}{|l}{ Input $=0,951 \mathrm{Log}=-173,713$ Sig. $=0.000$} \\
\hline
\end{tabular}

Tabela 2: Atuação do "grau" nas palavras de base nominal

O resultado nesta amostra segue o padrão identificado anteriormente, de tendência à realização africada nas 
palavras com sufixo -inho, o que reforça a necessidade de averiguar a interação dos processos fonológicos de nasalização e palatalização, como já apontado em Freitag (2015a).

Os resultados dos fatores linguísticos - vozeamento e interação com a nasalização - apontam que palavras como doidinha apresentam maior probabilidade de realização africada do que palavras como direito.

Semelhantemente ao encontrado nesta análise, Mota (2008b) verificou que a palavra muito e suas flexões foram as que mais condicionaram à realização das africadas baianas na fala de quase todos os informantes das quatro capitais do nordeste: Aracaju, Recife, Maceió e Salvador. A autora justifica esse resultado da faixa etária e anos de escolarização dos informantes. Embora a frequência de uso da palavra proporcione uma recorrência muito mais das africadas baiana, isso não significa que nessa palavra não haja estigma. O que acontece é que, conforme Bybee (2001), as palavras com uma alta frequência têm representações mais fortes e são mais facilmente acessadas e menos propensas a sofrer avaliações, a frequência com que as palavras individuais são usadas e que certos padrões se repetem na língua acaba afetando a representação mental e, em alguns casos, a forma fonética real das palavras. Ainda para Bybee (2001), se as 
representações fonéticas forem modificadas gradualmente, as palavras de alta frequência mudarão a uma taxa mais rápida do que as palavras de baixa e o efeito disso é automatizar a produção, visto que para autora, qualquer atividade motora repetida muitas vezes se torna mais eficiente.

O que acontece é que, como vimos, a consoante surda /t/ antecedida por glide é mais propensa de ser palatalizada e a palavra muito e suas flexões têm um uso bastante frequente na fala.

\section{FATORES SOCIAIS E PRAGMÁTICOS}

Se o controle dos fatores linguísticos se mostra estável, corroborando o que se identifica em estudos anteriores, o controle de fatores de natureza social e pragmática sinaliza para a hipótese de que a variante africada é considerada como um estereótipo na comunidade. Apresentamos os resultados relativos à análise dos dados de muito e flexões e das demais palavras, separadamente, em função dos fatores sociais e pragmáticos selecionados como estatisticamente significativos para o fenômeno.

Antes, porém, discutimos o resultado relativo ao tipo de coleta de dados. Embora não tenha sido selecionado como estatisticamente significativo, a distribuição dos percentuais deste fator nas outras palavras exceto muito e flexões sinaliza 
que a realização africada é ligeiramente mais produtiva nas interações do que nas entrevistas, sugerindo o efeito da formalidade/informalidade da situação (tabela 4). Já o muito e flexões apresenta comportamento relativamente estável, com percentuais de aplicação muito próximos (tabela 3).

\begin{tabular}{|l|c|c|}
\hline Tipo de coleta & Apl./total & Percentual \\
\hline Interação & $1061 / 1185$ & $89 \%$ \\
\hline Entrevista & $499 / 546$ & $91 \%$ \\
\hline
\end{tabular}

Tabela 3: Atuação do tipo de coleta em muito e flexões

\begin{tabular}{|c|c|c|}
\hline Tipo de coleta & Apl./total & Percentual \\
\hline Interação & $556 / 640$ & $87 \%$ \\
\hline Entrevista & $146 / 149$ & $98 \%$ \\
\hline
\end{tabular}

Tabela 4: Atuação do tipo de coleta nas demais palavras

As análises estatísticas dos dois grupos (muito e flexões e outras palavras) tiveram os mesmos fatores sociais e pragmáticos selecionados. Para muito e flexões, as variáveis selecionadas foram local de residência e distância social (proximidade/distância) entre participantes, respectivamente; já nas demais palavras, os fatores que condicionaram a aplicação da regra, respectivamente, foram o vozeamento, local de residência, distância social (proximidade/distância) entre participantes e "grau" das palavras de base nominal. Ao contrário do que esperávamos, o sexo/gênero não foi estatisticamente significativo. 


\section{LOCAL DE RESIDÊNCIA}

Resultados distribucionais do processo de palatalização de oclusivas alveolares apontam fronteiras sociais e dialetológicas no português falado no Brasil. Em amostra do Atlas Linguístico do Brasil (ALIB), composta por 32 informantes (oito de cada capital), divididos em duas faixas etárias (I - de 18 a 30 anos e II - de 50 a 65 anos), sexo/ gênero e duas faixas de escolarização (ensino fundamental e universitário), a distribuição diatópica da variação /t/ /t J/ e /d/ /d3/ antecedidos de glide é relativamente polarizada em Maceió e Aracaju (MOTA, 2008a).

\begin{tabular}{|c|c|r|r|r|}
\hline Capital & Faixa etária & Aplicação/total & Percentual & Peso relativo \\
\hline \multirow{2}{*}{ Recife } & I & $11 / 154$ & $7 \%$ & 0,17 \\
\cline { 2 - 5 } & II & $37 / 283$ & $13 \%$ & 0,36 \\
\hline \multirow{2}{*}{ Maceió } & I & $36 / 154$ & $23 \%$ & 0,55 \\
\cline { 2 - 5 } & II & $239 / 301$ & $79 \%$ & 0,95 \\
\hline \multirow{2}{*}{ Aracaju } & I & $17 / 121$ & $14 \%$ & 0,43 \\
\cline { 2 - 5 } & II & $67 / 195$ & $34 \%$ & 0,66 \\
\hline \multirow{2}{*}{ Salvador } & I & $1 / 108$ & $1 \%$ & 0,04 \\
\cline { 2 - 5 } & II & $31 / 214$ & $14 \%$ & 0,35 \\
\hline
\end{tabular}

Tabela 5: Realização africada de /t/ e /d/ em contextos antecedidos de semivogal quanto às capitais e faixas etárias (MOTA, 2008a, p.5)

Os alunos que estudam no Atheneu Sergipense são oriundos de diferentes municípios da região conhecida por Grande Aracaju. Na amostra constituída, no entanto, os informantes residem em Aracaju, Nossa Senhora do Socorro, 
São Cristóvão e Barra dos Coqueiros. Estes municípios constituem a região metropolitana de Aracaju, reconhecida oficialmente por meio da Lei Complementar Estadual n. 25/1995. Nos últimos anos, a região metropolitana vem passando por um significativo aumento populacional, que levou à criação da zona de expansão na região limítrofe entre Aracaju e São Cristóvão. O aumento populacional decorre de migrantes das regiões rurais do próprio estado de Sergipe, assim como de Alagoas e norte e nordeste da Bahia.

Inicialmente, controlamos o município de residência dos informantes como uma variável; como os resultados foram polarizados, com forte restrição à variante africada em Aracaju, amalgamamos os dados dos demais municípios sob o rótulo de região metropolitana. Do ponto de vista socioeconômico, há uma distinção bem clara entre Aracaju e os demais municípios. Por exemplo, o Índice de Desenvolimento Humano (IDH) de Aracaju é de 0,770, enquanto o dos demais municípios está na casa dos 0,60 (Barra dos Coqueiros 0,649; Nossa Senhora do Socorro 0,664 e São Cristóvão 0,662).

Ademais, em nossas observações, identificamos que os alunos fazem distinção entre morar em Aracaju e morar na região metropolitana. Em uma sondagem, um dos informantes que residia na Taiçoca, bairro de Nossa Senhora 
do Socorro, disse, em tom jocoso, que estava lá "só até o apartamento da 13 ficar pronto" (13 de Julho, bairro de classe média alta nas adjacências da instituição escolar).

\begin{tabular}{|l|l|l|l|}
\hline Localidade & Apl./total & $\%$ & PR \\
\hline Aracaju & $1146 / 1216$ & $94 \%$ & 0,60 \\
\hline Região & $483 / 587$ & $82 \%$ & 0,29 \\
\hline \multicolumn{4}{|c|}{ Input $=0,903$ Log $=-539.362$ Sig. $=0.024$} \\
\hline
\end{tabular}

Tabela 7: Atuação da localidade de residência em muito e flexões.

\begin{tabular}{|l|l|l|l|}
\hline Localidade & Apl./total & $\%$ & PR \\
\hline Aracaju & $404 / 418$ & $97 \%$ & 0,70 \\
\hline Região & $299 / 372$ & $80 \%$ & 0,28 \\
\hline \multicolumn{4}{|c|}{ Input $=0,951 \mathrm{Log}=-173,713$ Sig. 0.000} \\
\hline
\end{tabular}

Tabela 8: Atuação da localidade de residência nas demais palavras.

A realização oclusiva, independentemente do tipo de palavra, é influenciada pelo local de residência dos informantes, com 0,60 em muito e 0,70 nas demais palavras em Aracaju, e desfavorecida, com 0,29 em muito e 0,28 nas demais palavras na região metropolitana.

Evidência da variação diatópica na região metropolitana, especificamente em São Cristóvão, advém do estudo de Andrade, Evangelista, Santana (2016): com metodologia dialetológica (questionário), em uma amostra de 6 indivíduos por região, os resultados apontam o predomínio da variante africada (tabela 9). 


\begin{tabular}{|l|l|l|}
\hline & Aplic./Total & $\%$ \\
\hline Rita Cacete & $26 / 52$ & $50,0 \%$ \\
\hline Pedreira & $32 / 54$ & $59,3 \%$ \\
\hline Eduardo Gomes & $26 / 54$ & $48,1 \%$ \\
\hline Centro & $32 / 47$ & $68,1 \%$ \\
\hline Colônia Miranda & $24 / 53$ & $45,3 \%$ \\
\hline
\end{tabular}

Tabela 9: Distribuição da variante africada em São Cristóvão (ANDRADE; EVANGELISTA; SANTANA, 2016, p.637).

O bairro mais próximo de Aracaju é Eduardo Gomes, limítrofe no conglomerado urbano, enquanto o Centro de São Cristóvão fica a cerca de $17 \mathrm{~km}$ de distância. A distribuição polarizada capital/adjacência é mais uma evidência do comportamento de estereótipo para a variante africada.

\section{DISTÂNCIA SOCIAL}

Segundo Brown e Levinson (2011[1987]), a distância social é um fator significativo no contexto de polidez, uma vez que a relação existente entre os interlocutores influenciará na escolha linguística e na qualidade da interação. Esse comportamento social contribui para a tendência de o falante ser mais polido com quem tem menos familiaridade e ser polido na interação pode se dar de diferentes maneiras; uma delas é quando interagimos com alguém com quem não tenhamos proximidade, a tendência é que haja um maior monitoramento em nossa fala.

Neste estudo, a manifestação da polidez pode se dar pelo menor percentual de realização africada, considerando que 
a variante é um estereótipo. Do mesmo modo, quando os informantes são próximos um do outro, é possível que se monitorem menos e deixem emergir o seu vernáculo, por conta da informalidade e familiaridade.

\begin{tabular}{|l|l|l|l|}
\hline Distância Social & Apl./total & $\%$ & PR \\
\hline Próximo & $606 / 686$ & $88 \%$ & 0,48 \\
\hline Distante & $455 / 499$ & $91 \%$ & 0,53 \\
\hline $\begin{array}{c}\text { Input }=0,903 \text { Log }= \\
-539.362 \text { Sig. }=0.024\end{array}$ & & & \\
\hline
\end{tabular}

Tabela 10: Atuação da distância social em muito e flexões.

\begin{tabular}{|l|l|l|l|}
\hline Distância Social & Apl./total & $\%$ & PR \\
\hline Próximo & $326 / 403$ & $81 \%$ & 0,31 \\
\hline Distante & $230 / 237$ & $97 \%$ & 0,79 \\
\hline \multicolumn{2}{|c|}{ Input $=0,951$ Log $=-173,713$ Sig. $=0.000$} \\
\hline
\end{tabular}

Tabela 11: Atuação da distância social nas demais palavras.

Os resultados apontam a tendência à realização africada nas relações mais próximas, de modo mais acentuado nas demais palavras do que em muito e flexões. Pela alta frequência de uso da palavra muito, é possível pensar que o processo é mais avançado no item lexical. Já nas demais palavras, a polarização fica mais acentuada. Nas interações em que os participantes não têm proximidade, houve maior monitoramento do uso da variante africada; por não se conhecerem antes, os interlocutores, possivelmente tenham tentado ao máximo mostrar a sua face positiva com o intuito, mesmo que inconsciente, de ter uma aprovação positiva, 
ou seja, de ter uma imagem socialmente prestigiada, já que a variante é considerada um estereótipo avaliado de forma negativa por parte da comunidade.

Os resultados acima apresentados mostram que a variável pragmática distância social condiciona a aplicação da regra das africadas influenciando também no tipo de discurso (+ monitorado ou - monitorado). Embora Mota (2008b) tenha realizado um trabalho utilizando uma metodologia diferente da adotada nesta pesquisa, os seus resultados mostraram que maior ou menor frequência de uso das variantes africadas depende do grau de monitoramento. Na cidade de Aracaju, a autora constatou que em contextos mais monitorados houve uma baixa frequência de africadas, no entanto em contextos menos monitorados (espontâneos) a frequência das africadas baianas aumentou. Diante disso, podemos dizer que as variáveis distância social (proximidade e distancia dos informantes) e tipo de discurso (mais monitorado e menos monitorados) estão interligados e são favorecedores da variantes africadas.

\section{CONSIDERAÇÕES FINAIS}

A análise de um fenômeno do estereótipo na comunidade de práticas Atheneu Sergipense, a partir de duas amostras coletadas segundo duas metodologias distintas, uma de 
interação conduzida em rede social, conforme estabelecido por Araujo, Santos e Freitag (2014), e a outra de entrevistas sociolinguísticas aos moldes labovianos, permitiu averiguar os efeitos pragmáticos que atuam na variação, especialmente aqueles relacionados à preservação de faces.

Os resultados mostraram que a palavra muito e suas flexões apresentou um comportamento diferenciado no repertório linguístico dos informantes diante das demais palavras, pois pela significativa ocorrência do fenômeno na palavra muito e suas flexões em relação às demais, poderíamos entender que esta parece uma forma não marcada no grupo, e que seria menos propícia à avaliação negativa entre os membros, apresentando certa neutralidade em seu uso.

Os resultados também mostraram que os fatores internos apresentam comportamento estável no fenômeno, seguindo o que já fora identificado em outros estudos, como Freitag (2015a).

Em relação à distância social dos informantes, o monitoramento, ou preservação de face positiva, se dá quando os interlocutores são distantes, pois uma das estratégias de preservação de faces é o monitoramento linguístico, especialmente relacionado à emergência de estereótipos na fala, pois a face que apresentamos para o outro nas interações que estabelecemos é o que faz com que nossa autoimagem seja construída socialmente, seja de forma positiva ou negativa. Isso se reflete no uso da variante 
africada: entre indivíduos com maior distanciamento, o peso relativo é de 0,21 , já entre os indivíduos de maior proximidade, o peso relativo é de 0,69. Tais resultados reforçam que a variante é um estereótipo de estigma social na comunidade.

No entanto, cabe ressaltar que os resultados aqui apresentados não retratam todas as comunidades de práticas, visto que cada comunidade tem suas peculiaridades e constrói por meio também da linguagem a sua identidade, conforme mostram os estudos sobre palatalização em ambiente progressivo realizados em Sergipe, como os de Souza Neto (2014), Freitag e Santos (2016), Freitag (2015) e Freitag et al (2016), que uma mesma variante linguística pode receber valorações sociais diferenciadas a depender da comunidade.

\section{REFERÊNCIAS}

ANDRADE, T. R. C; EVANGELISTA, F. R. S; SANTANA, R. R (2016). "A palatalização das oclusivas dentais /t/ e /d/ no município de São Cristóvão". Web-Revista Sociodialeto, 6(18), 622-637, ARAUJO, A; SANTOS, K. C.; FREITAG, R. M. K (2014). "Redes sociais, variação linguística e polidez: procedimentos de coleta de dados". In: FREITAG, R. M. K. (Org.). Metodologia de coleta e manipulação de dados em Sociolinguística, São Paulo: Blücher, p.99-116.

ARAUJO, A. S., FREITAG, R. M. K (2015). "A forma de futuro do pretérito no português do Brasil e a função de polidez". Forma y Función, 1(28), 79-97. BATTISTI, E (2014). "Redes sociais, identidade e variação linguística". In: FREITAG, R. M. K. (Org.). Metodologia de coleta e manipulação de dados em Sociolinguística. São Paulo: Blücher, p.79-98. 
BROWN, P.; LEVINSON, S (2011[1987]). Politeness: some universals in language usage. Cambridge: Cambridge University Press.

BYBEE, J. L (2001). "Phonology and language use". Language Variation and Change, 14, Cambridge: Cambridge University Press.

CORRÊA, T.R.A.; RIBEIRO, C.C.S. (2018) "Avaliação social da palatalização de /t, d/ em Sergipe". A Cor das Letras, 19, n.Especial, 105-119.

ECKERT, P.; MCCONNELL-GINET, S. (2010). “Comunidades de práticas: lugar onde co-habitam linguagem, gênero e poder (1992)". In: OSTERMANN, A. C; FONTANA, B. F. Linguagem Gênero Sexualidade. Clássicos traduzidos. São Paulo: Parábola Editorial , p.93-108.

FREITAG, R. M. K. (2015b). "(Re)discutindo sexo/gênero na sociolinguística". In FREITAG, R. M. K.; SEVERO, C. G. (Orgs.). Mulheres, Linguagem e Poder Estudos de Gênero na Sociolinguística Brasileira. São Paulo: Blücher, p.1774.

FREITAG, R. M. K. (2013). "Banco de dados falares sergipanos". Working Papers em Linguística, 14(2), 156-164.

FREITAG, R. M. K. (2015a). "Socio-stylistic aspects of linguistic variation: schooling and monitoring effects". Acta Scientiarum. Language and Culture, 37(2) 127-136.

FREITAG, R. M. K., et al (2016). "Avaliação e variação linguística: estereótipos, marcadores e indicadores em uma comunidade escolar". In: FREITAG, R. M. K.; SEVERO, C. G.; GÖRSKI, E. M. (Orgs.) Sociolinguística e política linguística: olhares contemporâneos. São Paulo: Blücher, p.141160.

FREITAG, R. M. K.; MARTINS, M. A.; TAVARES, M. A. (2012). "Bancos de dados sociolinguísticos do português brasileiro e os estudos de terceira onda: potencialidades e limitações". Alfa, 56, 917-944.

FREITAG, R. M. K.; SANTOS, A. (2016). "Percepção e atitudes linguísticas em relação às africadas pós-alveolares em Sergipe”. In: LOPES, N. S.; ARAÚJO, S. S.; FREITAG, R. M. K. (Orgs.). A Fala Nordestina: entre a sociolinguística e a dialetologia. São Paulo: Editora Blucher, p.109-122.

LABOV, W. (2008[1972]). Padrões sociolinguísticos. São Paulo: Parábola Editorial. 
LEITE, C. M. B. (2011). "Estereótipos sociais e suas implicações para os estudos sociolinguísticos”. Estudos da Língua(gem) (Impresso), 9, 71-90. MENDONÇA, J. J.; FREITAG, R. M. K. (2016). "Primeira pessoa do plural com referência genérica e a polidez linguística". Soletras, 31, 39-57. MOTA, J. A. (2002). "O Atlas Linguístico do Brasil (ALIB) e os estudos geolinguísticos no Brasil. Signum". Estudos de Linguagem, Londrina, 5, 365-374.

MOTA, J. A. (2008a). "Como fala o nordestino: a variação fônica nos dados do Projeto Atlas Linguístico do Brasil". In: LIMA-HERNANDES, M. C. et al (Org.). A língua portuguesa no mundo. São Paulo: FFLCH-USP.

MOTA, Jacyra (2008b). "A metodologia na pesquisa geolinguística: o questionário fonético-fonológico". Prolíngua (João Pessoa), 2, 1-11.

SANKOFF, D.; TAGLIAMONTE, S.; SMITH, E. (2005). Goldvarb X: A variable rule application for Macintosh and Windows. Department of Linguistics of University of Toronto, Department of Mathematics of University of Ottawa.

SANTOS, K. C.; FREITAG, R. M. K. (2016). "Efeitos de polidez na variação na primeira pessoa do plural”. Veredas, 19, 136-159.

SOUZA NETO, Antônio Felix de (2014). Realizações dos fonemas /t/ e /d/ em Aracaju - SE. São Cristóvão: Editora UFS.

TAGLIAMONTE, S. A. (2006). Analysing sociolinguistic variation. Cambridge University Press.

Thaís Regina de Andrade Corrêa é mestranda em Letras na área de concentração em estudos linguísticos pela UFS. Membro ativo do Grupo de Estudos em Linguagem, Interação e Sociedade (Gelins) desde 2012. Email thayss_andrade@hotmail.com 